\title{
An upgraded version of the Eta model
}

\author{
Fedor Mesinger $\cdot$ Sin Chan Chou $\cdot$ Jorge L. Gomes $\cdot$ Dusan Jovic $\cdot$ \\ Paulo Bastos $\cdot$ Josiane F. Bustamante $\cdot$ Lazar Lazic $\cdot$ André A. Lyra • \\ Sandra Morelli · Ivan Ristic $\cdot$ Katarina Veljovic
}

Received: 28 July 2011 / Accepted: 8 January 2012 / Published online: 26 February 2012

(C) The Author(s) 2012. This article is published with open access at Springerlink.com

\begin{abstract}
Upgrades implemented over a number of years in an open source version of the Eta model, posted at the CPTEC web site http://etamodel.cptec.inpe.br/, are summarized and examples of benefits are shown. The version originates from the NCEP's Workstation Eta code posted on the NCEP web site http://www.emc.ncep.noaa.gov/ mmb/wrkstn_eta, which differs from the NCEP's latest operational Eta by having the WRF-NMM nonhydrostatic
\end{abstract}

Responsible editor: C. Simmer.

F. Mesinger $(\square)$

Earth System Science Interdisciplinary Center (ESSIC),

University of Maryland, College Park, MD, USA

e-mail: fedor@essic.umd.edu

F. Mesinger

Serbian Academy of Sciences and Arts, Belgrade, Serbia

S. C. Chou - J. L. Gomes - J. F. Bustamante - A. A. Lyra INPE Center for the Weather Prediction and Climate Studies (CPTEC), Cachoeira Paulista, SP, Brazil

D. Jovic

NCEP Environmental Modeling Center, Camp Springs,

MD, USA

P. Bastos

Brazilian Air Force, Brasilia, DF, Brazil

L. Lazic $\cdot$ K. Veljovic

Institute of Meteorology, University of Belgrade,

Belgrade, Serbia

S. Morelli

Department of Physics, University of Modena

and Reggio Emilia, Modena, Italy

I. Ristic

Weather2Umbrella Co., Belgrade, Serbia option included. Most of the upgrades made resulted from attention paid to less than satisfactory performance noted in several Eta results, and identification of the reasons for the problem. Others came from simple expectation that including a feature that is physically justified but is missing in the code should help. The most notable of the upgrades are the introduction of the so-called sloping steps, or discretized shaved cells topography; piecewise-linear finitevolume vertical advection of dynamic variables; vapor and hydrometeor loading in the hydrostatic equation, and changes aimed at refining the convection schemes available in the Eta. Several other modifications have to do with the calculation of exchange coefficients, conservation in the vertical diffusion, and diagnostic calculation of $10-\mathrm{m}$ winds. Several examples showing improved performance resulting from the dynamics changes are given. One includes a case of unrealistically low temperatures in several mountain basins generated by a centered vertical advection difference scheme's unphysical advection from below ground, removed by its replacement with a finitevolume scheme. Another is that of increased katabatic winds in the Terra Nova Bay Antarctica region. Successful forecast of the severe downslope zonda wind case in the lee of the highest peaks of the Andes is also shown, and some of the recent successful verification results of the use of the upgraded model are pointed out. The code is used at numerous places, and along with setup information it is available for outside users at the CPTEC Eta web site given above.

\section{Introduction}

The objective of this paper is to summarize changes introduced in the Eta code starting from the one available 
at the NCEP's so-called Workstation Eta site, at http://www.emc.ncep.noaa.gov/mmb/wrkstn_eta, to arrive at the code posted at the CPTEC's site http://etamodel. cptec.inpe.br/. This code we will refer to as the upgraded Eta. Motivations for most of the upgrades made resulted from attention paid to unsatisfactory performance noted in one or another aspects of various Eta results and identification of the reasons for the problem. Those for others came from simple expectation that including a feature that is physically justified and seems important but is missing in the code should help.

A brief summary of the original NCEP-posted Workstation Eta code seems in order. Features of its dynamical core include the eta vertical coordinate (Mesinger 1984), resulting in quasi-horizontal coordinate surfaces, and thus prevention of pressure-gradient force errors due to steep topography that can occur with terrain-following coordinates. Forward-backward scheme is used for time differencing of the gravity-wave terms, modified so as to suppress separation of solutions on two C-subgrids of the model's E-grid (Mesinger 1974; Janjic 1979; Mesinger and Popovic 2010). The Arakawa approach is used in space differencing, with conservation of enstrophy and energy, as defined on the C-grid, in horizontal advection within the nondivergent barotropic part of the flow (Janjic 1984), thereby enforcing a strong constraint on the false systematic cascade of energy toward smaller scales. Energy is conserved in transformations between the potential and the kinetic energy in space differencing (Mesinger 1984; Mesinger et al. 1988, Appendix, done by Dusanka Zupanski). Lateral boundary conditions are prescribed along a single outer line of grid points at the inflow points; at the outflow points tangential velocity components are extrapolated from inside of the model domain, with no boundary relaxation (Mesinger 1977). Finally, the Janjic et al. (2001) nonhydrostatic option of the WRF-NMM is included in this NCEP Workstation Eta code.

The physics package of the code includes a choice of two convection schemes, Betts-Miller-Janjic (Betts and Miller 1986; Janjic 1994), and Kain-Fritsch (Kain 2004); Ferrier cloud microphysics scheme (Ferrier et al. 2002); GFDL radiation schemes (Lacis and Hansen 1974; Schwarzkopf and Fels 1991); Noah land surface scheme (Chen et al. 1997); Monin-Obukhov similarity within the surface layer with Paulson stability functions, coupled to molecular sublayer over land and ice according to Zilitinkevich (1995), and over water according to Janjic (1994); wind direction dependent form drag scheme (Mesinger et al. 1996); turbulence transports above the surface layer using the Mellor-Yamada 2.5 closure (Mellor and Yamada 1982; see also Janjic 1990), with various refinements including the discovery of the reason for its realizability problem and the way of addressing it described in Mesinger (1993; summary in 2010), modified subsequently by Janjic (2002). As to the last point, note that with the original Mellor-Yamada 2.5 scheme for some combinations of parameters it is not possible to calculate turbulence kinetic energy change because the denominator of a ratio that needs to be evaluated turns out to be very close to zero; this tends to be referred to as a "realizability problem".

The accompanying pre-processing package was designed primarily to interpolate the initial fields off NCEP's Global Forecasting System (GFS) and use the GFS forecast initialized at the same time for the lateral boundary conditions. The post-processing code is in its latest NCEP state for the most part described in Chuang and Manikin (2001).

The summary of upgrades in the sections to follow will be organized in the usual order of dynamics followed by physics, with some examples of impact shown along the way. Within dynamics, a major change to be presented is that of the introduction of "sloping steps", or of a discretized/"poor man's" version of the shaved cells of Adcroft et al. (1997). Use of the piecewise-linear vertical advection of dynamic variables will come next. This makes the code approximately finite-volume, given that flux-type schemes are then used for all dynamics variables, and that in horizontal sides of the cell volumes are very nearly equal due to the use of the eta coordinate. Several points having to do with the calculation of exchange coefficients, conservation in the vertical diffusion, and diagnostic calculation of 10-m winds will follow. Vapor and hydrometeor loading in the hydrostatic equation will end the dynamics part.

Within physics, efforts of refining the two Eta convection schemes received more attention. The motivation and changes made will be summarized. The upgrades address the model's well-established problem of underdoing the heavy rain thresholds when the Betts-Miller-Janjic convection scheme is used. Vertical momentum fluxes were added to the Kain-Fritsch convection scheme. The molecular sublayer treatment was refined by making the molecular sublayer depth dependent on the roughness Reynolds number, following a suggestion of Brutsaert (1982).

The paper will end with an example of a severe downslope zonda wind case in the lee of the highest peaks of the Andes as forecast by the upgraded Eta, followed by a short discussion and concluding comments.

\section{Dynamics: sloping steps}

Very early in the modern era of the primitive equation modeling it was understood that the possibility of large errors in the calculation of the pressure gradient force when using terrain-following (sigma) coordinates needs attention. The earliest attempt of addressing the problem was 
that of the vertical interpolation from sigma back to constant pressure surfaces (Kurihara 1968). Downsides of this are that with no finite difference equation code can hardly be efficient, and that energy conservation in transformations between the potential and kinetic (as done, e.g., in Mesinger et al. 1988, Appendix) cannot be enforced. Perhaps worse, extrapolation of pressure underground will be required at some of the wind points next to topography slopes. Thus, we are not aware of this being used in more recent times.

Numerous methods of addressing the problem have subsequently been proposed; the review paper of Mesinger and Janjic (1985) summarizes those published at the time and the downsides involved. Of the methods proposed since the one by Lin (1997) appeared novel and seemed to stand out. But it was pointed in Mesinger (2004a) that as used in Lin (1998), it also amounted to vertical interpolation and thus in fact not a solution. If, instead, pressure gradient force is calculated based on information available at cell boundaries, the situation is not changed compared with that of sigma system schemes. In summary, there is a steepness limit to the validity of approximations to the pressure gradient force when using the sigma system, this limit being exceeded for slopes of sigma surfaces beyond a threshold value (Mesinger 2004a; see also Janjic 1977). Since the steepness of the topography will increase as the resolution is increased, increasing resolution does not help.

For a remedy, the radical move to a step-topography system with quasi horizontal coordinate surfaces (Mesinger 1984) was implemented in the NCEP Eta model, and according to several experiments appeared to have led to quite significant increases in skill (Mesinger and Black 1992; Mesinger 2000, among others). Yet, little movement away from the terrain-following coordinates ensued. On the contrary, considerable notice was taken of the poor result of a 10-km Eta in a 1997 case of the Wasatch windstorm, while the sigma system MM5 did well (McDonald et al. 1998), and in particular of a result of the paper by Gallus and Klemp (2000). Quite a widespread interpretation was that the eta coordinate is "ill suited for high resolution prediction models". For example, the presentation of Mesinger (2004b) displays a list of five references containing this or a similar statement.

There is a strong indication that the interest in quasi-horizontal coordinates is on the increase in recent years, originally sparked by the shaved cells approach of Adcroft et al. (1997), and used subsequently by Steppeler et al. (2006) and Walko and Avissar (2008). The standard step-topography eta has been used in more recent efforts as well; note Marshall et al. (2004), and in particular Russell (2007).

The problem of the step-topography eta had with the Wasatch downslope windstorm and with the flow over the witch of Agnesi topography (Gallus and Klemp 2000) is hard to dispute. However, as opposed to their being due to high resolution or the eta coordinate itself, a simple explanation of these problems was offered by Mesinger and Jovic (2004), as illustrated below.

Note that the eta coordinate is defined by an equation, relating eta to pressure and surface pressure. The steps are only the simplest discretization of topography using the coordinate, but other discretizations are possible. For a discussion, in Fig. 1, following Mesinger and Jovic (2004), a schematic is presented of a $2 \mathrm{D}$ section of an eta grid with step-mountain discretization.

Suppose that in Fig. 1 we are looking at a section of the lee slope with the air flow that ought to be downward along the slope according to the continuous equations. Note that with the step-mountain discretization what is imposed on the flow are eta vertical velocities of zero at the surface pressure points, $p_{\mathrm{s}}$ and horizontal velocities of zero at the velocity points, $v$, at the sides of steps. In Gallus and Klemp (2000) experiment flow separation occurred in that instead of descending in the lee the flow continued essentially horizontally; "step corners" seemed to have been blamed by Gallus and Klemp for the problem. While the discretized flow is not explicitly aware of the step corners, the boundary conditions at the sides of steps could be interpreted as implying the corners.

In analyzing the situation let us refer to grid boxes above by the indices of the temperature points, T. From the box 1 the flow enters box 2 to the right of it. The situation considered being such that the flow should move down the lee slope, the flow will move downward by way of the eta vertical velocity at the interface between the boxes 2 and 5 .

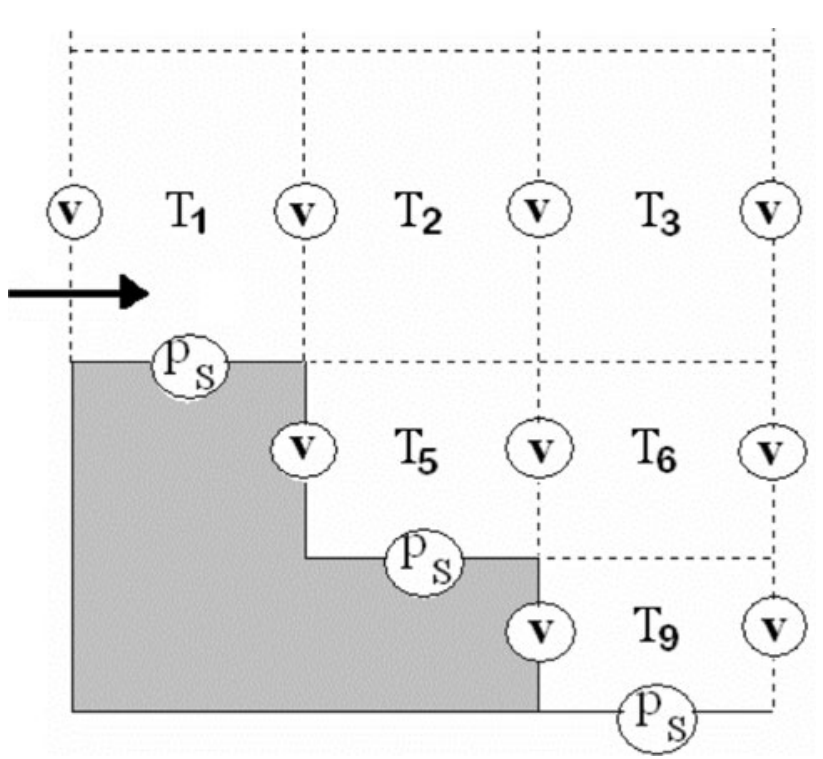

Fig. 1 Schematic used for the proposed explanation of the eta stepmountain discretization problem. The arrow denotes the direction of the flow used in the discussion 
However, some of the air that entered box 2 will move horizontally into box 3 .

What is missing is the flow going directly from box 1 into 5, which would have existed had the discretization accounted for the terrain slope between boxes 1 and 5. As a result, not all of the air which should have moved slantwise from box 1 directly into box 5 gets to it, since some of it is erroneously deflected horizontally from box 2 to into box 3 . The remedy we implemented is to allow for slopes by relaxing the boundary conditions referred to above.

If the eta vertical velocity is in some way allowed at $p_{\mathrm{S}}$ points, the pressure tendency equation becomes

$\frac{\partial p_{\mathrm{S}}}{\partial t}=-\int_{0}^{\eta_{\mathrm{S}}} \nabla \cdot\left(\mathbf{v} \frac{\partial p}{\partial \eta}\right) d \eta-\left(\dot{\eta} \frac{\partial p}{\partial \eta}\right)_{\mathrm{S}}$,

replacing (2.8) of Mesinger et al. (1988). Here and further on, $t$ stands for time,

$\eta=\frac{p-p_{\mathrm{T}}}{p_{\mathrm{S}}-p_{\mathrm{T}}} \eta_{\mathrm{S}}$

with

$\eta_{\mathrm{S}}=\frac{p_{\mathrm{rf}}\left(z_{\mathrm{S}}\right)-p_{\mathrm{T}}}{p_{\mathrm{rf}}(0)-p_{\mathrm{T}}}$

being the eta vertical coordinate, $p$ being pressure, the subscripts $\mathrm{T}$ and $\mathrm{S}$ standing for the top and the surface values of the model atmosphere, respectively; $z$ is geometric height, and $p_{\mathrm{rf}}(z)$ is a suitably defined reference pressure as a function of $z$. Finally, the dot superscript is used to denote the individual time derivative.

Optimum discretization of (1) is not obvious. The approach chosen by Mesinger and Jovic aims to maintain the Eta reliance on its existing Arakawa-type conservation features, for which it was felt desirable to avoid creating box volumes next to topography of very small volumes. In this way it was felt a more robust code should be obtained, from both the conservation and CFL points of view.

With this restriction, still various options are available. The option used by Mesinger and Jovic is that of defining topography slopes at the $\mathbf{v}$ points, the highest of those that are blocked in the step-mountain discretization. With this approach, slopes are defined if one of the four surrounding topography, $h$, points ( $p_{\mathrm{S}}$ points in Fig. 1$)$ is the highest of the four and thus responsible for blocking with the present discretization; and if two nearest neighbors of these $h$ points are the highest. Otherwise, the slope is set to remain zero. Slopes are considered discrete, so as to be valid over a grid square bound by centers of the four neighboring $h$ boxes in horizontal, and to define a topography descent down one layer depth, from the higher identified $h$ point or points to the lower ones of the four. Thus, in the schematic of Fig. 1, for the discretization of
(1) and other relevant equations or terms, the step topography is considered replaced by straight lines connecting the two pairs of neighboring $p_{\mathrm{S}}$ points. Slantwise mass divergence contributions are evaluated and incorporated in the calculation of the first term on the right side of (1). Note that this scheme does not require specification of the eta vertical velocity in (1), as slantwise mass transports in fact account for the second term on its right side. In addition, slantwise temperature advection has been added, consistent with the advection of mass; we shall describe the scheme used later in this section.

An example of the resulting sloping steps vertical grid is shown in Fig. 2. The $\mathbf{v}$ box immediately above the slope exchanges momentum with the $\mathbf{v}$ boxes of two layers at its right side, with half of what used to be the vertical side of the step at the lower left of the schematic now considered open. At the same time, there is a direct slantwise temperature exchange between temperature boxes denoted by $\mathrm{T} 1$ and $\mathrm{T} 4$ in the figure.

The result of Mesinger and Jovic's emulation of the Gallus-Klemp experiment is shown in Fig. 3. Its left panel shows a reproduction of their Fig. $6 \mathrm{a}$. This result is obtained using a full 3D Eta code, dynamics only, running a square domain, with variables prescribed not to change in the direction of one of its diagonals. Flow separation in the lee as seen in this panel was considered by Gallus and Klemp illustration of the Eta downslope windstorm problem; just as in their plot, a velocity of only between 1 and $2 \mathrm{~m} \mathrm{~s}^{-1}$ is seen in the left panel plot immediately behind

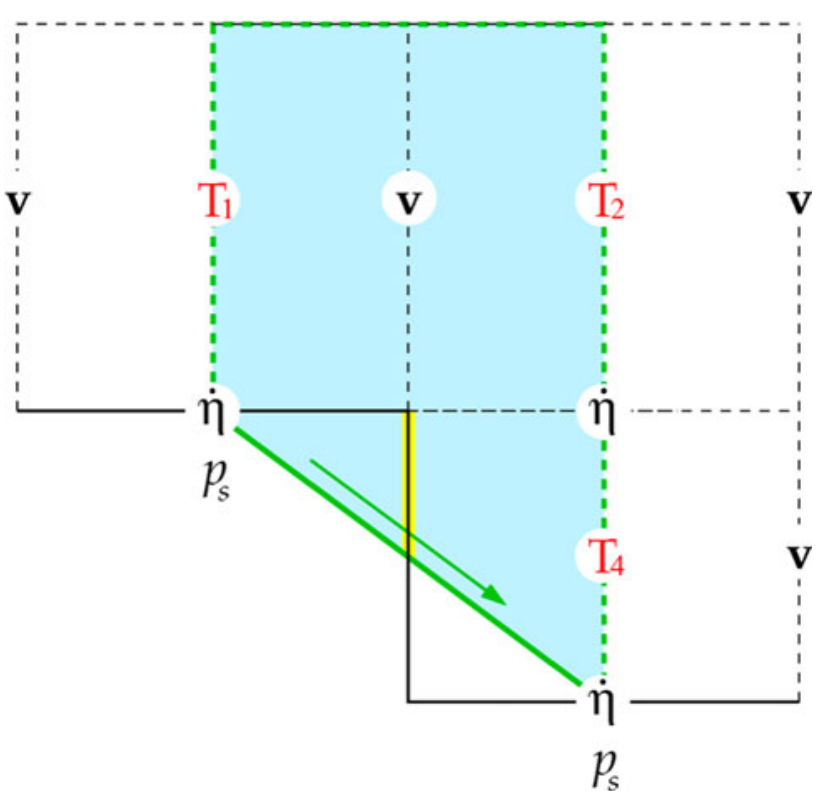

Fig. 2 Schematic of the vertical grid of the sloping steps eta discretization used. Slantwise momentum and temperature transport occurs along half of what used to be the vertical side of the left lower box with the step-topography eta discretization 


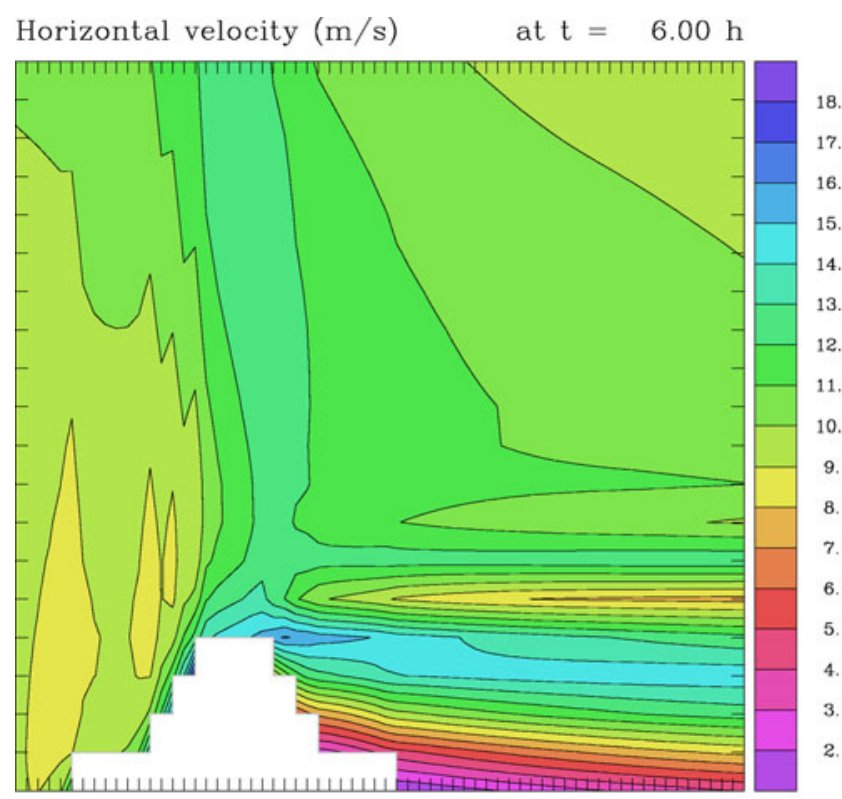

CONTOUR FROY 2 TO 18 BY 1

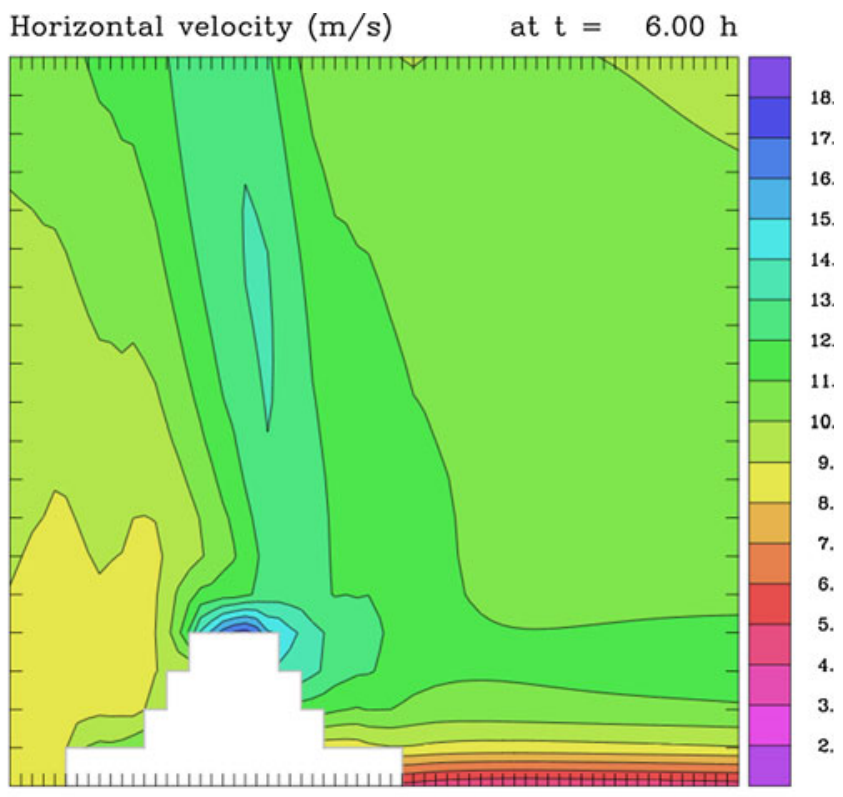

CONTOUR FROM 2 TO 18 BY 1

Fig. 3 Gallus-Klemp experiment, with parameters chosen so as to mimic the results shown in Gallus-Klemp (2000) Fig. 6a. Control, left panel; code using sloping steps eta discretization, right panel

the obstacle next to the ground. In the right panel, obtained using the outlined sloping steps discretization, a considerably greater velocity is seen in the lee next to the ground, of between 4 and $5 \mathrm{~m} \mathrm{~s}^{-1}$.

It should be pointed out that our experiment shown in Fig. 3 was run using hydrostatic code, since the code we have put together for running 2D-like experiments did not have the nonhydrostatic option. One should expect that greater wave amplitude and thus also stronger downslope wind would have been obtained using nonhydrostatic code (e.g., Reinecke and Durran 2009). This expectation is consistent with the results of our forecast experiments on the zonda downslope windstorm, to be shown in Sect. 9, which we did run using our more recent code with the nonhydrostatic option available, and with its nonhydrostatic option set to both off and on, respectively.

In the original version of the sloping steps code a standard "Lorenz-Arakawa" centered vertical advection scheme (Arakawa and Lamb 1977)

$\frac{\partial T}{\partial t}=\cdots-\dot{\eta} \overline{\frac{\partial T}{\partial \eta}}^{\eta}$

was used for the slantwise temperature advection. Using this scheme, in a 48-h forecast over a domain centered over complex western United States topography, running an 8 -km/60-layer code, a problem was noted of quite unrealistic very low temperatures developing in two mountain basins. This result is shown in Fig. 4. The two basins standing out and responsible for the extremely wide temperature range chosen by the plotting routine, one in southern Montana and the other in western Alberta, each contain two grid boxes with temperatures below $190 \mathrm{~K}$.

It was felt that the problem had to be due to an instability-like mechanism which is clearly possible with the scheme if an inversion were to develop in a basin of one-layer depth, and upward velocity were to prevail at a basin's grid cell upper interface. If the temperature on top of this bottom cell were not to change much, which might be expected given that it is affected by the horizontal advection as well, then the temperature of the bottom cell would keep decreasing, as if there was vertical advection of still colder air from below ground. This would make the inversion stronger, and as it gets stronger, the faster it will grow.

Given that with the outlined sloping steps scheme we know precisely how much mass is being transported via slantwise vertical advection from one cell to another, and also what is the mass of individual grid cells, changing the vertical advection into a conserving finite-volume Lagrangian advection was in principle not a problem. Once this was done and the problem forecast rerun, the unrealistic temperatures did not appear any more.

The scheme as summarized can be considered a simplest discretized version of the shaved cells scheme of Adcroft et al. (1997). It obviously can be made more general such as to have slopes extend over more than just the bottoms of two the neighboring layers; but we are not convinced that the extra effort and in particular the computational cost of having this in place is cost beneficial. An attractive feature of the scheme as put together is its simplicity of 
Fig. 4 Lowest layer temperatures obtained when using scheme (2) for the slantwise temperature advection, in a 48-h forecast verifying at 1200 UTC 11 December 2005

\section{VALID 11 Dec 2005 12Z Sunday} 20051209 12UTC $48 \mathrm{~h}$ fest

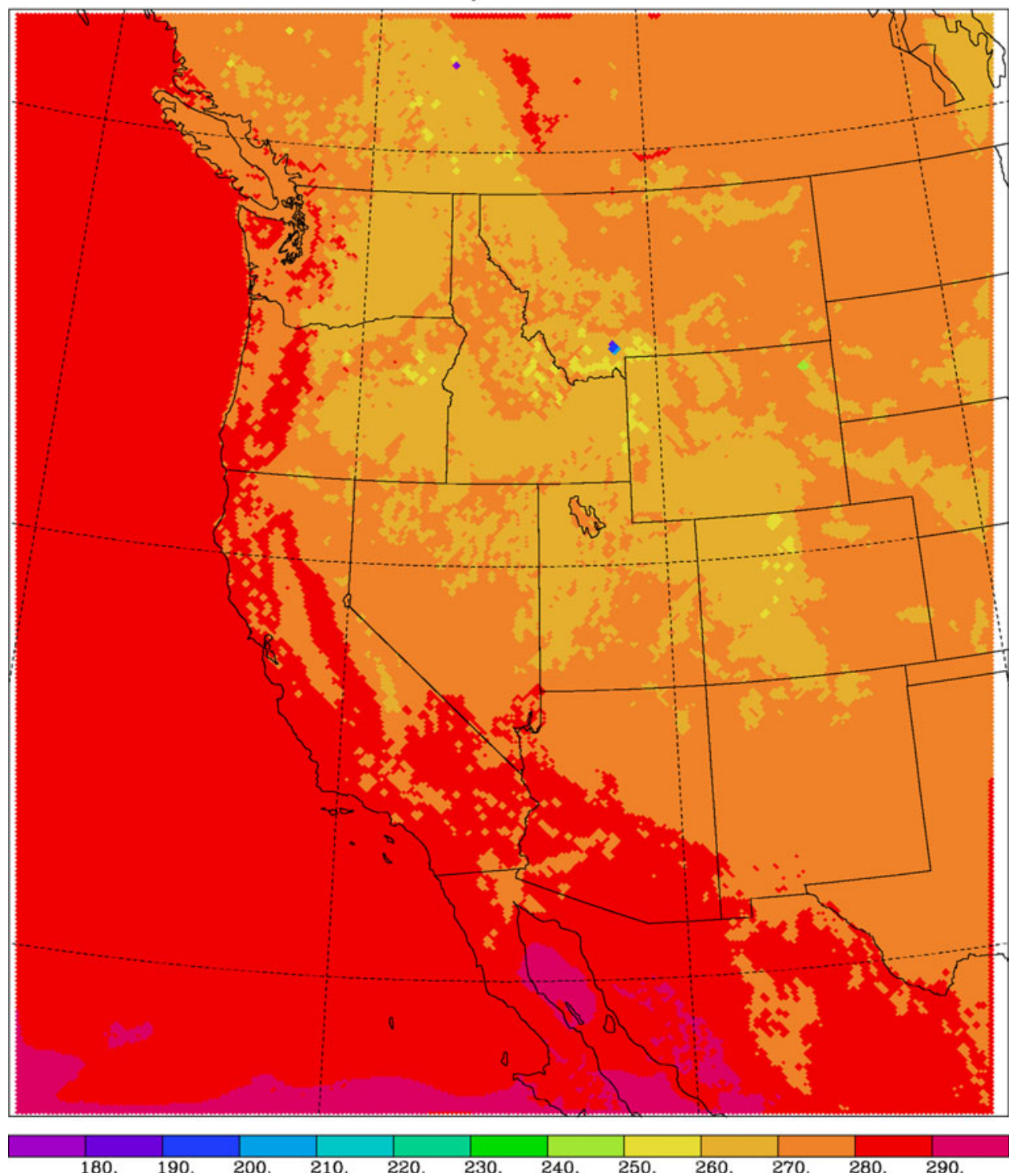

implementation, as code-wise it is an add-on to the existing step-topography Eta, with an option to engage it via a switch. The code is in use at a number of places, in some of them operationally, and in yet others in regional climate projects, with a very large number of runs completed. The robustness of the code seems thus to have been confirmed to within a high level of confidence.

\section{Piecewise linear vertical advection of dynamic variables}

Once the problem referred to above with highly unrealistic bottom layer temperatures in two basins was addressed by a change from finite-difference to a conserving finite-volume scheme, we looked at the difference in bottom layer temperatures between the forecast done with this improved sloping steps code, and the one using the standard steptopography Eta. This difference is shown in pages 18-19 of Mesinger et al. (2008). It ranges about -3 up to $7 \mathrm{~K}$, with these large difference values still typically found in various basins.

That large difference between two extensively tested codes and in specific places is puzzling. We feel that the very likely culprit must be once again the finite-difference scheme (2), given that its problem with false advection from below ground has been identified and found that harmful in the original sloping steps code.

The motivation for abandonment of (2) in favor of a finite-volume scheme for the vertical advection of dynamic variables-velocity components and temperature-is also that this makes the Eta very nearly a finite-volume code. 
This is because of the use of the flux-type schemes in horizontal, and of the vertical sides of the grid cells with the eta coordinate being very nearly equal, so that the result would not change much if the fluxes were to be explicitly multiplied by the cell side areas in the calculation of the new cell values as needs to be done in strictly finite-volume schemes.

An attractive feature of the finite-volume design is the idea that finite-volume schemes are consistent with the way physics is applied in models, namely considering grid point values as averages for the grid box as opposed to point samples of differentiable functions. Thus, finite-volume schemes are not detrimentally affected the way finite difference schemes are by the grid point to grid point noise that tends to be generated by physical forcings and therefore can be expected to be advantageous compared to finite-difference schemes. It has been suggested earlier (e.g., Mesinger 2004b) that the lack of a clear evidence of the benefit from high Taylor-series type accuracy schemes in full physics forecasts is suggestive of the relevance of this issue and can be interpreted as encouraging a move toward finite-volume schemes. Note also the advocacy of the finite-volume approach by Lin (2004) for its satisfying the need for conservative scalar transports, as well as the earlier experiments of abandoning the finite-difference vertical advection of momentum and temperature in favor of a flux-limited scheme by Thuburn (1993).

The finite-volume scheme of our choice for the vertical advection of velocity components and temperature is the piecewise linear scheme of Mesinger and Jovic (2002). This is an iterative scheme in which at each iteration slopes at cells that are not maxima or minima are adjusted toward the boundary values of neighboring cells as much as possible without enabling creation of new extrema given that the boundary values of neighboring cells will be adjusted in the same way. Experiments have shown that very little is gained by doing more than three iterations.

There are of course a number of other options of designing a piecewise linear advection scheme. These schemes tend to be referred to as Van Leer type schemes (e.g., Durran 1999). Three standard Van Leer schemes have been tested in Mesinger and Jovic (2002) for advection of a top-hat function, compared with the described Mesinger and Jovic scheme. Tests have demonstrated that the Mesinger and Jovic scheme performed better than each of the three Van Leer schemes. It also performed better than the scheme used in the WRF-NMM, as well as better than the Takacs' 3rd order "optimally" upstream biased scheme (Takacs 1985). As a result, the Mesinger and Jovic scheme has been used for some years for the vertical advection of passive scalars in the Eta model.

The impact of the changed vertical advection will be illustrated in the next section by an example in which it is used along with that of the sloping steps, and the change to be described next, affecting momentum exchange coefficients.

\section{Surface exchange coefficients, $10-\mathrm{m}$ winds, and conservation in the vertical diffusion}

An issue of the Eta model is one of the lowest layer winds at height points, in between the four wind points, that are used for calculation of surface exchange coefficients. In NCEP operational Eta codes as a result of complex history in the averaging of winds surrounding a height point winds that are blocked because of being defined on vertical sides of steps and thus considered equal to zero are not taken into account. Thus, higher wind speeds are obtained than those that would have been obtained had all the four winds been averaged. In CPTEC and many other Eta codes a centered four-point averaging is always used. Thereby obtaining a fictitiously too high wind speed value at height points next to blocked winds is avoided. There is evidence that the NCEP uncentered averaging was leading to higher than justified surface exchange coefficients, which in turn was resulting in lower lowest layer wind speeds.

It seems that the history referred to above owes its complexity to the fact that the NCEP Eta post-processor is calculating $10-\mathrm{m}$ winds at height points. We have seen indications that in regions of complex topography this has led to underestimation of $10-\mathrm{m}$ wind speeds. In addition, we have found it more appropriate to have $10-\mathrm{m}$ winds calculated at wind than at height points. One can in fact note by considering an idealized topography that with $10-\mathrm{m}$ winds diagnosed at height points the normally lower winds inside basins and valleys get overrepresented compared with those at the neighboring higher steps. For example, with a one-dimensional simplest "extremely rough" topography consisting of a one-cell step, a two-cell basinthe smallest permitted, another one-cell step, etc., there are twice as many lowest layer wind points over steps than inside basins, while the reverse is true for winds diagnosed over height points. Thus, $10-\mathrm{m}$ winds over wind points are not only physically more appealing, they will also avoid this overrepresentation problem. We have therefore modified the calculation of the $10-\mathrm{m}$ winds so as to have them diagnosed at the wind points.

In Fig. 5 we show an example of the impact of the preceding code refinements in case of strong katabatic winds down the slopes of the glaciers of the Terra Nova Bay Antarctica region. The case is one of the development of a large polynya that generated identifiable mesoscale atmospheric events. The figure shows the wind speed cross section along the approximate direction of katabatic flow over the Reeves glacier, one flowing most directly into 
Fig. 5 Wind speed cross section, along the approximate direction of katabatic flow over the Reeves glacier, Antarctica, obtained using code without sloping steps and piecewise linear vertical advection, and height point wind averaging without including the blocked winds (left panel), and using the former two code modifications, and centered averaging of winds to calculate exchange coefficients (right panel). The simulation is initialized at 0000 UTC 15 July 2006, and the plots shown are valid at 2100 UTC the same day
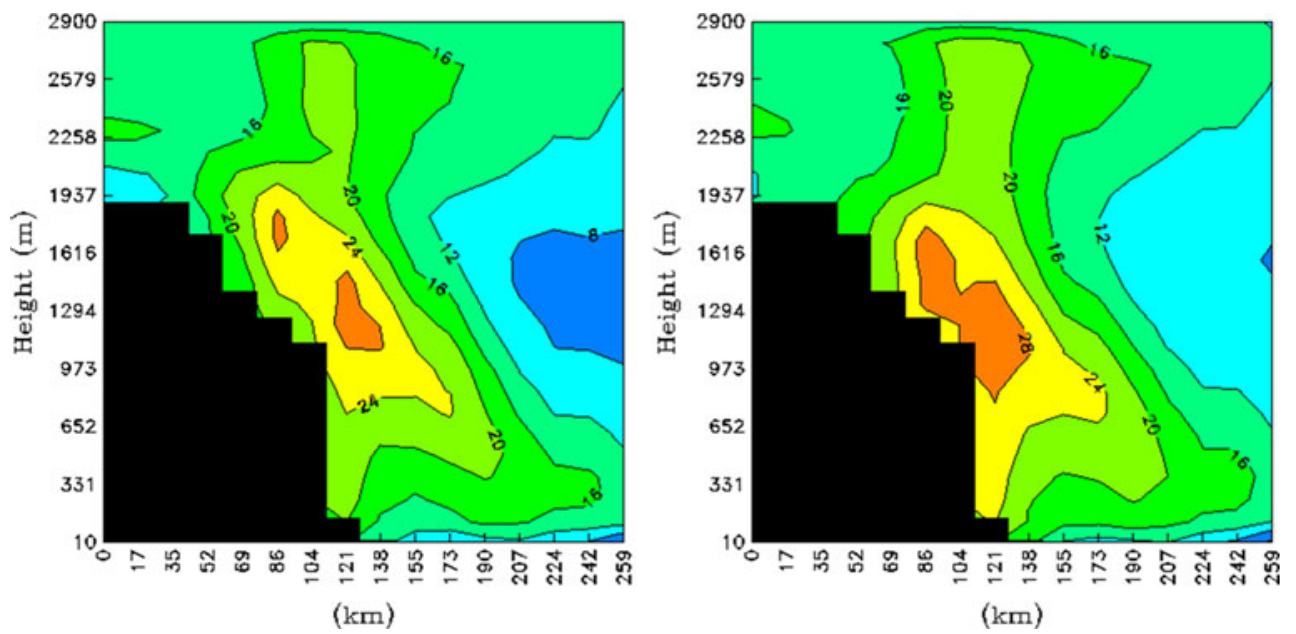

Terra Nova Bay. In its left panel wind speeds are shown obtained using the "standard" Eta code, without sloping steps, piecewise linear vertical advection of momentum and temperature, and the centered wind averaging at height points summarized just above, while in its right panel wind speeds are shown obtained using these three upgrades, respectively. The model topography is shown in solid black and wind speeds are in $\mathrm{m} \mathrm{s}^{-1}$.

While possibilities for verification in the Antarctica region are of course limited, there are thermal infrared radiometer (AVHRR) images and automatic station (AWS) data that confirm that the simulation illustrated in the righthand panel above gave a very good representation of a sequence of well-defined cyclonic structures that moved over the area during the period considered (Morelli and Parmiggiani 2012).

A plot in horizontal of the differences in the lowest layer wind speeds corresponding to those of Fig. 5 and including the area of its cross sections is shown in Fig. 6. In the plot, the thin red line delimits the continental iced land, on the left, from the Ross Sea, iced at the time, and the thick black line denotes the position of the cross section. The vectors of wind speed at the lowest layer above topography, obtained using the upgraded version of the Eta, are also plotted. They show that the wind is blowing from the continent towards the sea, descending down the steep topographic slopes that characterize the Antarctic coast. We can see that the differences in wind speeds over the complex terrain of the section shown are found that are even greater than those along the cross-section line. Values of more than $6 \mathrm{~m} \mathrm{~s}^{-1}$ are seen inside three closed contours south of that line, with the area they include colored in red, with even a speck of over $7 \mathrm{~m} \mathrm{~s}^{-1}$ within the southernmost of the three. Irrespective of the verification referred to above, these large wind speed increases in areas of strong katabatic winds seem welcome in view of the criticism of the step-topography Eta of not handling realistically

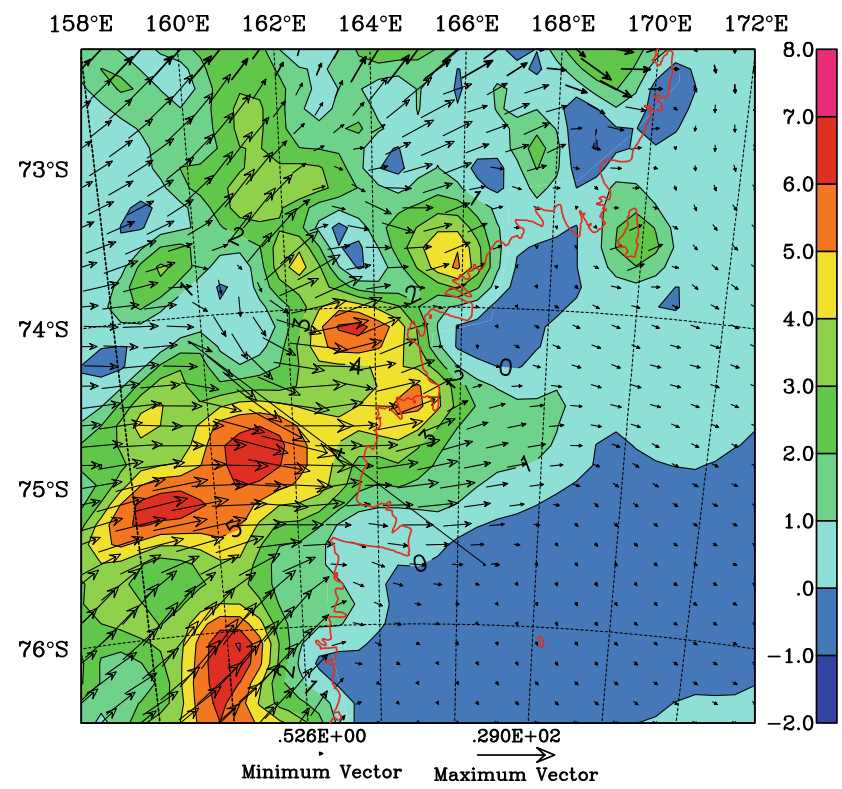

Fig. 6 Lowest layer wind speed difference, in $\mathrm{m} \mathrm{s}^{-1}$, resulting from the three changes summarized above-same as those that led to the change from the left to the right panel cross section of Fig. 5. Valid at the same time as Fig. 5. The iced land area is on the left of the coastal line, shown as a thin red line. The arrows represent the lowest layer wind vectors, as calculated by the upgraded version of the Eta. The black line denotes the position of the cross section of Fig. 5

downslope windstorms, as summarized in Sect. 2 (McDonald et al. 1998; Gallus and Klemp (2000); references in Mesinger (2004b).

Yet another refinement of our upgraded Eta code is the enforcement of the Arakawa-type conservation in the vertical diffusion. This is done using the standard technique (e.g., Arakawa and Lamb 1977) of writing the advective form of a difference equation so that it is equivalent to its flux form. For example, in case of the diffusion contribution to the time change of specific humidity, $q$, this amounts to replacing (5.1) of Janjic (1990) by 


$$
\begin{aligned}
\frac{q_{L}^{\tau+1}-q_{L}^{\tau}}{\Delta t}= & \frac{1}{\left(\rho \Delta_{\eta} Z\right)_{L}}\left[\left(\rho K_{\mathrm{H}} \frac{\Delta_{\eta} q}{\left.\overline{\Delta_{\eta} Z}\right)^{\eta}}\right)_{L+1 / 2}\right. \\
& \left.-\left(\rho K_{\mathrm{H}} \frac{\Delta_{\eta} q}{\overline{\Delta_{\eta} Z}}\right)_{L-1 / 2}\right] .
\end{aligned}
$$

Here, for simplicity, the time step superscripts, $\tau$, on the right-hand side have been omitted; $L$ is the layer subscript, increasing downwards; $\rho$ is density, $\Delta$ denotes the standard centered difference operator, with the subscript if any denoting the direction, and overbar the centered two point averaging; $Z$ is the layer interface elevation; and $K_{\mathrm{H}}$ is the heat exchange coefficient. If now the time step change of the vertical integral of moisture is calculated using the simplest difference form of the continuity equation, it can be verified that the total moisture will be conserved in the diffusion step.

\section{Water vapor sources and sinks and hydrometeor loading}

The eta system equations of (Mesinger 1984; also in Mesinger et al. 1988) were arrived at with effects of sources and sinks of water vapor and of the presence of liquid water/ice in the continuity equation neglected. We shall here generalize the equations so as to have these effects taken into account. For convenience, we first display the referred to equation set in their Mesinger et al. (1988) hydrostatic, frictionless, and adiabatic form:

$$
\begin{aligned}
& \frac{\mathrm{d} \mathbf{v}}{\mathrm{d} t}+f \mathbf{k} \times \mathbf{v}+\nabla \Phi+\frac{R T}{p} \nabla p=0, \\
& \frac{\mathrm{d} T}{\mathrm{~d} t}-\frac{\kappa T \omega}{p}=0 \\
& \frac{\partial}{\partial \eta}\left(\frac{\partial p}{\partial t}\right)+\nabla \cdot\left(\mathbf{v} \frac{\partial p}{\partial \eta}\right)+\frac{\partial}{\partial \eta}\left(\dot{\eta} \frac{\partial p}{\partial \eta}\right)=0 \\
& \frac{\partial \Phi}{\partial \eta}=-\frac{R T}{p} \frac{\partial p}{\partial \eta} \\
& \omega \equiv \frac{\mathrm{d} p}{\mathrm{~d} t}=-\int_{0}^{\eta} \nabla \cdot\left(\mathbf{v} \frac{\partial p}{\partial \eta}\right) \mathrm{d} \eta+\mathbf{v} \cdot \nabla p \\
& \frac{\partial p_{S}}{\partial t}=-\int_{0}^{\eta_{S}} \nabla \cdot\left(\mathbf{v} \frac{\partial p}{\partial \eta}\right) \mathrm{d} \eta \\
& \dot{\eta} \frac{\partial p}{\partial \eta}=-\frac{\partial p}{\partial t}-\int_{0}^{\eta} \nabla \cdot\left(\mathbf{v} \frac{\partial p}{\partial \eta}\right) \mathrm{d} \eta .
\end{aligned}
$$

Above, $\mathrm{d} / \mathrm{d} t$ is the individual time derivative, $f$ is the Coriolis parameter, $\mathbf{k}$ is the vertical unit vector, $\Phi$ is geopotential, $R$ is the gas constant, and $\kappa$ is $R / c_{\mathrm{p}}$, where $c_{\mathrm{p}}$ is the specific heat at constant pressure.

We consider first the water vapor sources and sinks in the continuity equation. To that end, consider the continuity equation with no mass sources or sinks, (5) above. We want to allow for the sources and sinks of water vapor, such as are generated by various precipitation and landsurface schemes. Following a standard mass budget consideration, we arrive at

$\frac{\partial}{\partial \eta}\left(\frac{\partial p}{\partial t}\right)+\nabla \cdot\left(\mathbf{v} \frac{\partial p}{\partial \eta}\right)+\frac{\partial}{\partial \eta}\left(\dot{\eta} \frac{\partial p}{\partial \eta}\right)-\frac{\mathrm{d} q}{\mathrm{~d} t} \frac{\partial p}{\partial \eta}=0$.

To obtain the surface pressure tendency equation we need to integrate (10) from the top to the bottom of the model atmosphere. To handle the singularity of evaporation at the surface, we integrate only to $\eta_{\mathrm{S}}-\varepsilon, \varepsilon$ being small, obtaining

$\frac{\partial p_{\mathrm{S}}}{\partial t}=-\int_{0}^{\eta_{\mathrm{S}}} \nabla \cdot\left(\mathbf{v} \frac{\partial p}{\partial \eta}\right) d \eta+\int_{0}^{\eta_{\mathrm{S}}-\varepsilon} \frac{\mathrm{d} q}{\mathrm{~d} t} \frac{\partial p}{\partial \eta} d \eta+g E$,

as a replacement of (8). Here $E$ is the mass of water vapor evaporated into the atmosphere per unit area and unit time.

Integrating (10) from 0 only to $\eta$, and rearranging terms, we obtain

$\dot{\eta} \frac{\partial p}{\partial \eta}=-\frac{\partial p}{\partial t}-\int_{0}^{\eta}\left[\nabla \cdot\left(\mathbf{v} \frac{\partial p}{\partial \eta}\right)-\frac{\mathrm{d} q}{\mathrm{~d} t} \frac{\partial p}{\partial \eta}\right] \mathrm{d} \eta$.

Note that this replaces (9).

Various hydrometeors if carried in a model, e.g., cloud water/ice, add weight to columns of air, affecting pressure. The total mass in a volume element $V$ is then

$m_{\mathrm{t}}=m_{\mathrm{d}}+m_{\mathrm{v}}+m_{\mathrm{w}}$,

where $m_{\mathrm{w}}$ is the mass of hydrometeors in the volume. A prognostic variable of the Eta is "specific cloud water/ice"

$w \equiv m_{\mathrm{w}} /\left(m_{\mathrm{d}}+m_{\mathrm{v}}\right)$.

It is convenient to define an effective density, the density of the mixture of moist air and hydrometeors,

$\rho_{\text {eff }} \equiv m_{\mathrm{t}} / V$.

Combined with (13) and (14), this gives

$\rho_{\text {eff }}=\rho(1+w)$.

Use of (16) in the hydrostatic equation, and in the mass convergence terms of the pressure tendency equation, instead of the air density, will account for the effects of the hydrometeor loading on pressure.

Given that in the Eta code the evaporated water vapor is not added explicitly to the atmosphere but instead the latent heat flux is used as a boundary condition for the vertical 
diffusion of moisture, the total column water vapor needs to be calculated before and after the diffusion loop, and the evaporation obtained as the difference between the two.

The suggestions that the precipitation mass sink may not be negligible in numerical models were made by a number of authors as of the early 1990s; for a review of those as well as the impact in two early simulations see Lackmann and Yablonsky (2004). We ran a test of the modifications of the present section on a case including the tropical cyclones Connie and Irma from the Australian Monsoon Experiment (AMEX), and obtained Connie central sea level pressure deeper by about $1 \mathrm{mb}$, along with an increased total precipitation at times up to about $15 \%$ (Mesinger and Lazic 2004). In the extensively documented study of the impact in the case of Hurricane Lilli (2002), Lackmann and Yablonsky (2004) show the sea level pressure near the storm center deeper by as much as $2-5 \mathrm{mb}$ when in their Eta simulation our mass sink modifications above are taken into account. Needless to say, this was accompanied by stronger cyclonic flow and heavier precipitation as well.

\section{Physics: Betts-Miller-Janjic convection}

Once most of the physics package of the Eta was put together at the end of the 1980s (Janjic 1990) in tests that followed a conspicuous problem encountered was that of runaway convection over warm water. This was addressed in Janjic (1994) by modifications of the Betts-Miller convection scheme via implementation of two mechanisms sensitive to the intensity of convection. The first included introduction of a nondimensional parameter

$E=$ const $_{1} \frac{\bar{T} \Delta S}{c_{\mathrm{p}} \sum \Delta T \Delta p}$

named "cloud efficiency". Here $\bar{T}$ is the mean temperature of the tentative cloud, averaged over the convection time step to be performed; $\Delta S$ is the change in cloud "entropy" integrated over cloud layers which would result if the convective adjustments of layer temperatures and humidities were to take place; $c_{\mathrm{p}}$ is the specific heat at constant pressure; summation in the denominator is over the cloud layers of depths $\Delta p$ of layer temperature changes $\Delta T$ to take place over the convection time step, and const $_{1}$ is a nondimensional constant. The denominator above is proportional to the precipitation generated in a convection time step; see Janjic (1994) for more detail. Thus, $E$ is proportional to the change in column entropy per unit precipitation produced.

As opposed to fixed predetermined reference humidity profile of the original Betts-Miller (BM) scheme, Janjic made the scheme choose its preliminary reference profile in between two sets, "fast" (or "dry") and "slow" (or "moist"), depending on the value of the parameter $E$. The fast profiles-defined by their values of the deficit of saturation pressure, dsp, change in pressure needed to achieve saturation, are multiplied by a prescribed factor $F_{\mathrm{S}}$ to obtain slow profiles. At the time $F_{\mathrm{S}}$ was assigned a value of 0.6. When $E$ is smaller, that is for heavier precipitation per unit entropy change, profiles chosen by the scheme will be closer to the slow profiles that have smaller magnitudes of dsp values. With smaller dsp magnitudes, the preliminary reference humidity profiles are wetter, and thus closer to saturation. Thus, a given column humidity profile, wetter than the reference in order to have convection, will be less different from the reference profile; and since the scheme has the change of specific humidity in an active convection time step proportional to the difference in specific humidities between the column and the reference values, the rate of precipitation will be smaller. Thereby the modified scheme is discouraging heavy convection.

The second mechanism introduced is the extension of scheme's relaxation time, depending also on the value of $E$. For heavier precipitation, when $E$ is smaller, the relaxation time was made to increase. With $E$ decreasing from its maximum to its minimum allowed value, the relaxation time was made to change linearly from its minimum prescribed value to one $1 / 0.7$ times greater. In this way this mechanism also discourages heavy convection.

Experimenting with two cases of heavy convection over warm water and using these changes, remarkably, Janjic succeeded in avoiding excessive precipitation in the case in which it was not justified, while not damaging the case in which it was. It was later discovered, however, that the Eta problem with excessive precipitation over warm water of the late 1980s was not caused by the Betts-Miller convection scheme, but by a faulty scheme for the surface heat transport. Once the surface fluxes scheme of Janjic (1990) was replaced by the "lbulk" scheme of Mesinger (Mesinger and Lobocki 1991; see also Mesinger 2010), the case of Janjic (1994) with heavy spurious precipitation was rerun using the original Betts-Miller scheme, and no spurious heavy precipitation was obtained. This result is shown in the essay on the Eta Cumulus Convection (BMJ) Scheme posted at http://etamodel.cptec.inpe.br/doc.shtml, where also more detail on various parameters and additional discussion is included.

The two mechanisms even so remained in place in NCEP's Eta code albeit the first one with a reduced intensity, by having the value of the parameter $F_{\mathrm{S}}$ increased to 0.85 . One should, however, note that irrespective of the motivation referred to above introduction of the two mechanisms can be looked upon as an attractive feature given that in parameterizing convection we are facing a lack of first principle equations so that in the manner 
of turbulence theory using a value of nondimensional parameter such as (17) so as to fit the experimental data seems justified.

A well-established and persistent problem of the Eta with the mechanisms and parameters as above is one of having an increasing deficiency of heavy precipitation with increasing precipitation thresholds, see, e.g., the plots in Mesinger (2008). But in about a month and half midsummer "inverted profiles experiment", using for the parameter $F_{\mathrm{S}}$ the value of 1.1 , this problem was removed (Eric Rogers, 2000, personal communication). In this spirit, various experiments were made at CPTEC with reversing one and/or the other of the two mechanisms, or with making one or the other of them neutral, insensitive to the tentative precipitation intensity. Both mechanisms are reversed in the Eta code at the time of this writing posted at its CPTEC site, so as to make them act in the direction of enhancing heavy convection, but we are encouraging users to make experiments to check if they find the choices suitable and also to consult the Essay referred to.

\section{Momentum transport with the Kain-Fritsch scheme}

The dynamics of convective systems are strongly controlled by the shear of the horizontal wind. Strong transports occur within deep convective clouds and modify the wind profile. Tiedtke (1989) showed that the inclusion of the momentum transports by convection in the ECMWF model strongly affected the rotational part of the flow in the tropics. Based on diagnostics from cloud-resolving model simulations, Gregory et al. (1997) developed a parameterization scheme of convective momentum transports which improved the global atmospheric circulation in the Unified Model.

The model has an option to use the Kain-Fritsch (Kain and Fritsch 1993; Kain 2004) cumulus parameterization scheme. This is a mass flux type scheme in which the convectively unstable cloud parcel rises and descends going through entrainment and detrainment processes in steady state. The scheme closure requires that $90 \%$ of the initial convective available potential energy (CAPE) be removed from the air column. The scheme distinguishes deep and shallow convection. The cloud base mass flux of deep cumulus is calculated from the grid-scale updraft, whereas the cloud base mass flux of shallow cumulus is dependent on the turbulent kinetic energy. Deep convection entrainment rate increases with parcel buoyancy and in a moister environment, and it is inversely proportional to detrainment rate.

Momentum transports are included in the Kain-Fritsch version of the Eta model (Bastos 2007). The environmental horizontal winds at the cloud base are taken as the cloud momentum. The scheme is using the entrainment and detrainment rates and cloud mass flux, updrafts and downdrafts calculated in the heating, and moistening part of the scheme. Below cloud base, convective fluxes of horizontal momentum decrease in $\ln p$ towards the surface, whereas in the layer above cloud top those fluxes detrain completely. Only downgradient momentum fluxes are considered. Similar to the heating and moisture tendencies, the horizontal wind tendencies due to convective fluxes (conv) are given by

$\left.\frac{\partial \bar{u}}{\partial t}\right|_{\text {conv }}=-\frac{\partial\left(\overline{\omega^{\prime} u^{\prime}}\right)}{\partial p}$
$\left.\frac{\partial \bar{v}}{\partial t}\right|_{\text {conv }}=-\frac{\partial\left(\overline{\omega^{\prime} v^{\prime}}\right)}{\partial p}$

where $\omega$ is the vertical velocity in pressure coordinates $\left(\mathrm{Pa} \mathrm{s}^{-1}\right), u$ and $v$ are the zonal and meridional wind components $\left(\mathrm{m} \mathrm{s}^{-1}\right)$, respectively, the overbar refers to grid scale resolved values and the prime refers to subgrid-scale values. The right-hand side terms refer to contributions of turbulent transports due to convection.

The discretized forms of the tendencies are given as

$$
\begin{aligned}
\left.\frac{\Delta \bar{u}}{\Delta t}\right|_{\mathrm{conv}}= & \frac{1}{\Delta p}\left[\left(\omega_{\mathrm{u} 2}+\omega_{\mathrm{d} 2}\right) \bar{u}_{2}-\left(\omega_{\mathrm{u} 1}+\omega_{\mathrm{d} 1}\right) \bar{u}_{1}\right. \\
& \left.+\left(\varepsilon_{\mathrm{u}}+\varepsilon_{\mathrm{d}}\right) \bar{u}_{\mathrm{m}}-\delta_{\mathrm{u}} u_{\mathrm{um}}-\delta_{\mathrm{d}} u_{\mathrm{dm}}\right] \\
\left.\frac{\Delta \bar{v}}{\Delta t}\right|_{\text {conv }}= & \frac{1}{\Delta p}\left[\left(\omega_{\mathrm{u} 2}+\omega_{\mathrm{d} 2}\right) \bar{v}_{2}-\left(\omega_{\mathrm{u} 1}+\omega_{\mathrm{d} 1}\right) \bar{v}_{1}\right. \\
& \left.+\left(\varepsilon_{\mathrm{u}}+\varepsilon_{\mathrm{d}}\right) \bar{v}_{\mathrm{m}}-\delta_{\mathrm{u}} v_{\mathrm{um}}-\delta_{\mathrm{d}} v_{\mathrm{dm}}\right]
\end{aligned}
$$

where $\varepsilon$ and $\delta$ are the entrainment and detrainment rates $\left(\mathrm{Pa} \mathrm{s}^{-1}\right)$, respectively, the subscript $m$ refers to layer mean value, subscripts 1 and 2 to the base and the top of the layer, and $u$ and $d$ to the updrafts and downdrafts, respectively.

Figure 7 shows the Equitable Threat Score (ETS) and the Bias Score (BS) of forecats over Southeast Brazil, verifying at 48 and $72 \mathrm{~h}$, calculated at 5-km resolution once per day for the period 3-9 December 2006. This is in the rainy season of the region. The scores are evaluated considering approximately 120 surface stations. The curves compare the runs with the original scheme (blue lines) against those with the convective momentum transports included (red lines). The ETS of the runs with the momentum transports exhibit higher values, especially at heavier precipitation rates, and the skill at $72 \mathrm{~h}$ shows less reduction with respect to the 48 -h forecasts. The BS indicates that the Kain-Fritsch scheme in the Eta model generally overestimates precipitation amounts at all rates. The BS curves show that the scheme with momentum transports reduces this overestimation at heavier precipitation rates. 


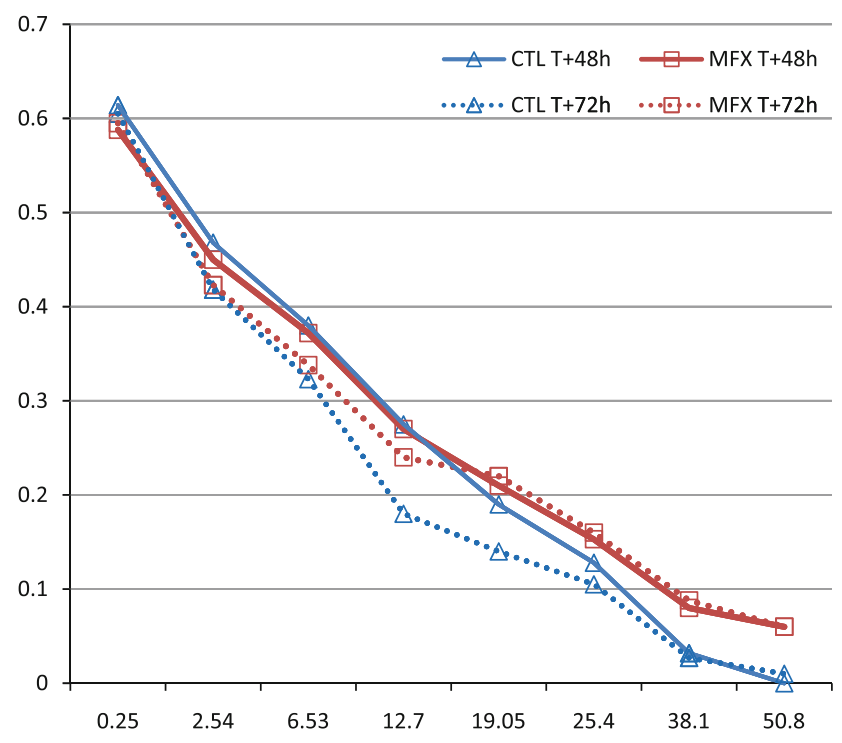

Fig. 7 Equitable Threat Score (left) and Bias Score (right) of Eta model forecasts of precipitation using the original Kain-Fritsch (triangles) and included momentum transports (squares) schemes,

The inclusion of the momentum transports causes small displacements in the precipitation areas with respect to the precipitation using the original scheme.

\section{Molecular sublayer thickness}

A nonstandard feature of the Eta PBL parameterizations is the explicit parameterization of the molecular sublayer over water (Janjic 1994). The parameterization is a constant-gradient approximation of the relations of Liu et al. (1979, LKB later on), with parameters based on the experimental data of Mangarella et al. (1973). Subsequent to the description of the scheme by Janjic (1994) it was, however, noticed that what was considered to be a free parameter of the scheme can in fact, for momentum transfer, be specified according to data compiled by Brutsaert (1982). This is our modification to be summarized here.

In Janjic parameterization the exponential smooth regime relationships of LKB with their gradual transition into the turbulent surface layer are replaced by molecular sublayers in which transports are determined entirely by molecular diffusion, matched to log profiles above in which transports are entirely turbulent. In addition, for chosen values of friction velocity, the sublayers for the three variables handled undergo discontinuous regime changes, from smooth to rough, and into "rough with spray", as suggested by experimental data of Mangarella et al. (1973). When switching from smooth to the rough regime the

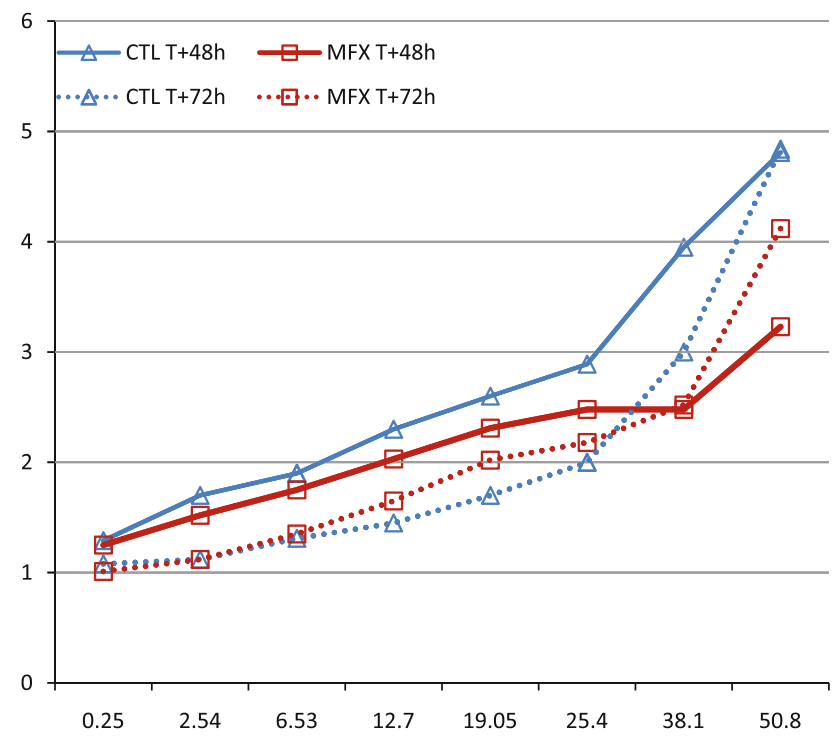

verifying at $48 \mathrm{~h}$ (solid lines) and $72 \mathrm{~h}$ (dotted lines), calculated over Southeast Brazil for the period 3-9 December 2006. Numbers along the abscissas show accumulated precipitation amounts in $\mathrm{mm} / 24 \mathrm{~h}$

sublayer for momentum is removed, while the thicknesses of the sublayers for the sensible and the latent heat fluxes are reduced to one-third of their smooth regime values. Switching into the rough with spray regime, these two sublayers are removed as well.

With the chosen two-layer approach, fluxes on top of the assumed molecular sublayers must be equal to those at the bottom of the turbulent layers. Thus, if the mean flow velocity, potential temperature, and specific humidity are denoted by $U, \Theta$, and $q$, respectively, and the subscript 1 is used to denote the values of variables at the tops of the molecular sublayers while the subscript $\mathrm{s}$ is used to denote those at the surface, we have

$$
\begin{aligned}
& v \frac{U_{1}-U_{\mathrm{s}}}{z_{1 \mathrm{u}}}=u_{*} u_{*}, \\
& \kappa \frac{\Theta_{1}-\Theta_{\mathrm{s}}}{z_{1 \theta}}=\theta_{*} u_{*}, \\
& \varepsilon \frac{q_{1}-q_{\mathrm{s}}}{z_{1 \mathrm{q}}}=q_{*} u_{*},
\end{aligned}
$$

where $v, \kappa$, and $\varepsilon$ are the kinematic viscosity, thermal diffusivity, and molecular diffusivity of water vapor, respectively, $u_{*}$ is the friction velocity, and $\theta_{*}$ and $q_{*}$ are analogously defined scaling parameters for the sensible heat and moisture fluxes, respectively. The right-hand sides of (18) can also be expressed in terms of the standard surface layer bulk relationships, and the equations thus obtained solved for $U_{1}, \Theta_{1}$ and $q_{1}$ provided sublayer thicknesses $z_{1 \mathrm{u}}, z_{1 \theta}$, and $z_{1 \mathrm{q}}$ are known. These were obtained by Janjic by postulating 
$\frac{z_{1 \mathrm{u}} u_{*}}{C v}=\frac{z_{1 \theta} u_{*}}{S \kappa}=\frac{z_{1 \mathrm{q}} u_{*}}{D \varepsilon}=\zeta$,

$C, S$, and $D$ here being parameters known as the inverse interfacial drag coefficient, and inverse interfacial Stanton and Dalton numbers, respectively, while $\zeta$ was considered to be a tuning parameter. The value of $\zeta=0.50$ was originally used (Janjic 1994). Values of for $U_{1}, \Theta_{1}$ and $q_{1}$ thus being determined, and the values at mid-point of the lowest model layer known, fluxes can be calculated using surface layer bulk formulae and the lowest layer transfer coefficients, available from the surface layer code of the model.

It was subsequently noted that the value of $\zeta$, for momentum transfer, can be determined from a procedure suggested by Brutsaert (1982, p. 90). One can ask a question: if the linear profile at the bottom of the molecular sublayer is linearly extrapolated upwards, and the logarithmic profile of the surface layer is at the same time logarithmically extrapolated downwards, at what elevation will the two extrapolated profiles intersect? This should be the appropriate value of $z_{1 u}$, from which $\zeta$ can be calculated. Brutsaert also gives the result for the nondimensional height used in his diagram, showing median of extensive experiments, as $z_{+}=u * z / v=11$. Thus,

$\frac{u_{*} z_{1 \mathrm{u}}}{v}=11$.

Combining this with the relation between $z_{1 \mathrm{u}}$ and $\zeta$ as defined by (19), we have

$\zeta=11 / C$.

The "surface renewal theory" (e.g., LKB, or SCOR WG 110,2000 , Sect. 7.3.2 C) postulates the existence of small eddies which intermittently transfer heat, etc. across the transition layer between the molecular and the fully turbulent layer. LKB have shown that Brutsaert's suggestion of the renewal time scale of these eddies being proportional to the time scale of the Kolmogorov eddies leads to

$C=G \operatorname{Rr}^{1 / 4}$

where $G$ is a proportionality constant, and $\operatorname{Rr}=z_{0} u_{*} / v$ is the roughness Reynolds number. Thus, we obtain

$\zeta=\frac{11}{G \operatorname{Rr}^{1 / 4}}$

as the relationship we have been looking for.

Fitting velocity and temperature laboratory data to their profile relationships LKB obtain for the smooth regime the value of $G$ close to 30, which is used by Janjic (1994). Our attempts to identify temperature and moisture profile data representations analogous to Brutsaert's momentum diagram that led to (22) have not been successful; thus, we are continuing to use the same value of $\zeta$ for all three fluxes. We have, however, replaced the use of a constant value of $\zeta$, of 0.35 in more recent NCEP Eta codes, by the value given by the relation (22). This should increase the fluxes for values of $\mathrm{Rr}$ greater than around 1 , and reduce those for smaller values of $\mathrm{Rr}$.

\section{A zonda windstorm case}

Given that, as summarized earlier, misperformance on a case of strong downslope winds, along with that of the Witch of Agnesi topography experiments of Gallus and Klemp led to a number of statements identifying the problems encountered as coming from the eta coordinate, an example of the performance of our upgraded code in a real data case of a strong downslope windstorm appears desirable.

We will to that end display results of the upgraded Eta forecast of a severe zonda wind event of 11 July 2006. Zonda is the wind down the slopes of the Andes well known in the area east of the highest peaks of the Andes Cordillera, at the latitudes north of $35^{\circ} \mathrm{S}$, where the Cordillera rises rapidly with several peaks over $6,000 \mathrm{~m}$, such as the Aconcagua Peak (6,959 m). During the zonda episodes the temperature at various lee stations is known to rise rapidly, within $6 \mathrm{~h}$ or so, to values 10 and $20^{\circ} \mathrm{C}$ greater than before, as a result of the foehn effect. San Juan (latitude $31^{\circ} 36^{\prime} \mathrm{S}, 630 \mathrm{~m}$ above sea level, ASL) and Mendoza $\left(32^{\circ} 51^{\prime} \mathrm{S}, 754 \mathrm{~m} \mathrm{ASL}\right)$ are two major population centers of the area affected by the phenomenon. Performance of the Eta in zonda situations has been discussed by Seluchi et al. (2003), and the case of July 2006 has been analyzed by Norte et al. (2008) and run using the RAMS (or, BRAMS, Brazilian RAMS) model. This was done using the "shaved cells" option of RAMS, with quasi-horizontal coordinate surfaces (Tremback and Walko 2004; Ana Graciela Ulke, 2007, personal communication). The two references on zonda cited provide a lot of information on zonda in general, and the latter one specifically on the case we have experimented with as well.

In Fig. 8 we are showing the vertical cross sections of temperature, in the model's west-east direction, with the left panel showing the situation $24 \mathrm{~h}$ after the initial time of 0000 UTC 10 July 2006, and the right panel the situation $9 \mathrm{~h}$ later, at $33 \mathrm{~h}$. The position of cross sections shown was chosen near the station of San Juan. Note that the local times at the time of the experiment are $3 \mathrm{~h}$ behind the UTC time; thus, the right-hand panel corresponds to the time of the middle panel of Fig. 15 of Norte et al. (2008). Yet, the comparison of the two results is not straightforward, with our plots showing regular temperature as opposed to the equivalent potential temperature of the Norte et al. plots, 


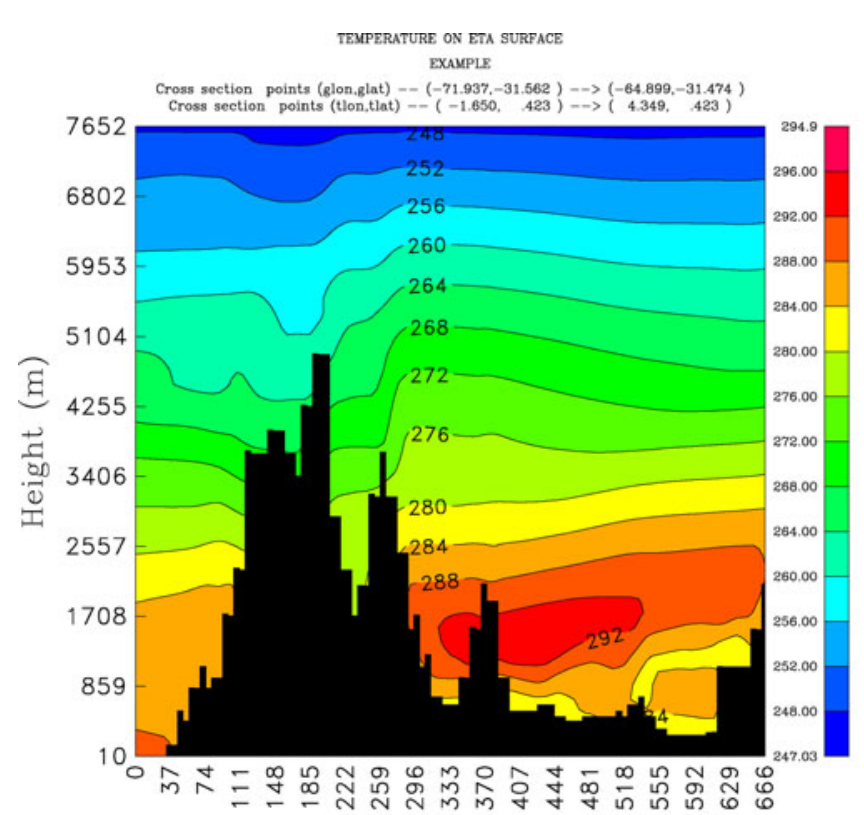

$(\mathrm{km})$

Fig. 8 Vertical cross sections of topography and temperature at $24 \mathrm{~h}$ after the initial time of the forecast, at 1200 UTC 10 July 2006, left panel, and at $33 \mathrm{~h}$, right panel, respectively, across the Andes at about

and the resolutions of the models run being different as well. The domain we used is of 2,637 $\times 2,924 \mathrm{~km}$ of the model's rotated longitude $\times$ latitude, with the grid distance of about $8.3 \mathrm{~km}$ along the model's grid equator, and less away from it, and 60 layers in the vertical. Just as those of our Figs. 4, 5, 6, the plots of Fig. 8 are made using the NCAR graphics package, with each model's grid point temperature or topography depicted with no interpolation, this permitting the extraordinary detail of the rough Andes topography of the place and of the model as used to be seen.

Comparing the values of temperatures of the two plots one can notice signs of an adiabatic ascent on the western upslope side of the Andes Cordillera with reduction of near-surface temperatures, and of an adiabatic warming on their downslope side, with considerable temperature increase during the $9 \mathrm{~h}$ of forecast time that have elapsed between the two plots. Temperatures of $<284 \mathrm{~K}$ are seen in the left-hand plot around the area of the San Juan station, chosen to be in the middle of the plot. Note that the Eta is a layer model, so that the temperatures depicted are layeraveraged temperatures, which holds also for the lowest grid cells next to the ground surface. In the right-hand plot in the same area, temperatures of more than $296 \mathrm{~K}$ are seen. With temperature contours chosen to be at 1-K intervals in the warmest regions of the plots (not shown) temperatures of more than $297 \mathrm{~K}$ have been seen to have occurred in the San Juan area. Thus, in the San Juan area, a zonda warming of about $14 \mathrm{~K}$ has been forecast, suggesting that with the upgrades implemented the Eta model is capable of realistic

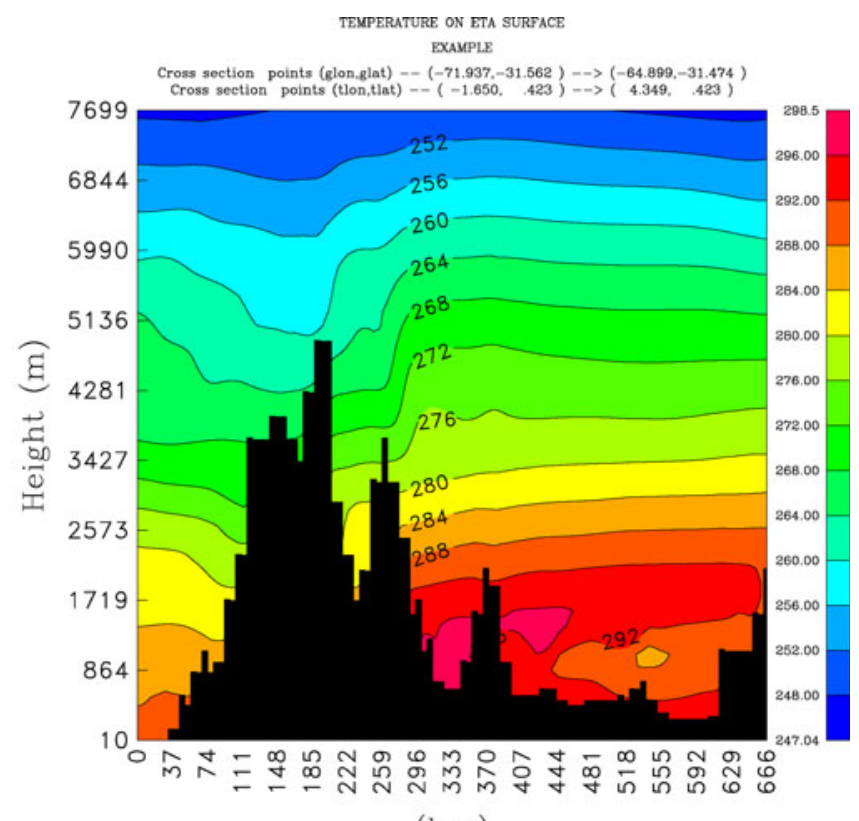

$(\mathrm{km})$

the place of their highest elevation. The code used is that of the upgraded Eta, with its nonhydrostatic option on

forecasts of downslope windstorms. With the maximum warming seen near the ground of the right-hand plot, there is also no sign of flow separation in the lee such as seen in the left-hand plot of Fig. 3. The extraordinary roughness of the topography encountered is also something we feel is worth taking note of.

We have also made an experiment in which we have created plots of Fig. 8 running the Eta with its nonhydrostatic option switched off. The results (not shown) were quite similar, but the zonda warming at the bottom of the major lee slope in the middle of the plots was about $1 \mathrm{~K}$ smaller than that of the nonhydrostatic experiment shown in Fig. 8.

\section{Work in progress, discussion, and concluding comments}

While we have in the preceding sections summarized model upgrades implemented within the code posted at its CPTEC web site, close cooperation with the group of the University of Athens, led by Professor George Kallos, needs to be mentioned. While perhaps not all of the upgrades we listed are included in the Athens code, going by the name Skiron, or Skiron/Eta, or Skiron/Dust, the Athens code is coupled to advanced aerosols/dust package, and has been used for numerous air quality studies as well as operational forecasts addressing several application areas (e.g., Kallos et al. 2007; Astitha et al. 2010; Spyrou et al. 2010; Zoras et al. 2010; among others). Specifically, 
the latest upgrade of the Athens code consists of the replacement of the GFDL radiation packages by the RRTMG radiation code which is a high priority for implementation also in our upgraded Eta code summarized here. Skiron, by the way, was the Greek god of the northwest wind, depicted on the Tower of the Winds in Athens.

Our plans foresee further refinements in a number of areas. This includes some of the features summarized; for example, work on the Kain-Fritsch cumulus parameterization scheme is still ongoing. Recently, a parameter dependent on resolution was introduced into the scheme to control the conversion of cloud liquid water or ice into convective precipitation (Gomes and Chou 2010) which improved the skill score of precipitation forecasts in cases of South Atlantic Convergence Zone and cold fronts.

The upgraded code described here is in use at a number of places, in some of them operationally, and in yet others in regional climate projects and for multidecadal runs (Chou et al. 2011), with a very large number of runs completed. The robustness of the code seems thus to have been confirmed to within a high level of confidence. As to the code verification via comparison versus results of other codes, we feel the results of the ensemble experiments of Veljovic et al. (2010) should be noticed. In these experiments, a 26-member Eta ensemble driven by ECMWF 32-day ensemble members achieved $250 \mathrm{hPa}$ wind scores, as verified against ECMWF analyses, about equal and most of the time slightly better than those of its global ECMWF driver members, in spite of absorbing the handicap of the unavoidable lateral boundary errors.

A final comment may be appropriate regarding our discussion of the attractiveness of the finite-volume approach in Sect. 3 and statement that with the replacement of the vertical advection scheme the upgraded Eta as a result of its flux-type schemes and the use of the eta coordinate has become approximately a finite-volume model. We wish to stress that the upgraded Eta because of the features of its Arakawa type schemes beyond those that just work with fluxes, such as conservation of energy and C-grid enstrophy, and conservation of energy in transformations between the kinetic and potential energy in space differencing, includes physically valuable properties that a standard finite-volume model will not have. Specifically, the former two features above prevent systematic transport of energy toward small scales within the two-dimensional nondivergent part of the flow, thereby removing a significant noise-generation mechanism that otherwise would exist. Thus, the upgraded Eta's dynamical core could well be referred to as a "finite-volume +" dynamical core.

Acknowledgments The upgraded Eta code documented here originates from the so-called "Workstation Eta" code that has been maintained by Mathew Pyle, of the NCEP Environmental Modeling Center (EMC), Camp Springs, MD. Some of the work reported upon has been partially funded by NCEP/EMC via the Cooperative Institute for Climate Studies (CICS) of the University of Maryland; and also by $\mathrm{CNPq}$, the Brazilian National Council for Scientific and Technological Development. Tom Black, also of EMC, has been for many years the lead Eta code developer, and is the principal developer also of its MPI version, indispensable in most of today's computer frameworks. Tom has provided advice essential for progress on a variety of issues. The Workstation Eta preprocessing and postprocessing packages derive from their original developments at the Federal Hydrometeorological Institute in Belgrade and were to a considerable degree further developed at the University of Athens, within the group led by George Kallos. Finally, the authors much appreciate the suggestions and comments of the three reviews received, one signed by Eugenia Kalnay, which led to significant improvements of the manusript.

Open Access This article is distributed under the terms of the Creative Commons Attribution License which permits any use, distribution, and reproduction in any medium, provided the original author(s) and the source are credited.

\section{References}

Adcroft A, Hill C, Marshall J (1997) Representation of topography by shaved cells in a height coordinate ocean model. Mon Weather Rev 125(9):2293-2315

Arakawa A, Lamb VR (1977) Computational design of the basic dynamical processes of the UCLA general circulation model. In: Chang $\mathbf{J}$ (ed) Methods in computational physics, vol 17. Academic Press, New York, pp 173-265

Astitha M, Kallos G, Spyrou C, O'Hirok W, Lelieveld J, Denier van der Gon HAC (2010) Modelling the chemically aged and mixed aerosols over the eastern central Atlantic Ocean-potential impacts. Atmos Chem Phys 10:1-26. doi:10.5194/acp-10-1-2010

Bastos PR (2007) Inclusão da perturbação de momentum no esquema de parametrização de cumulus Kain-Fritsch e impactos sobre um caso de chuva convectiva.MSc dissertation. Instituto Nacional de Pesquisas Espaciais, São José dos Campos

Betts AK, Miller MJ (1986) A new convective adjustment scheme. Part II: Single column tests using GATE wave, BOMEX and Arctic air-mass data sets. Q J R Meteorol Soc 112:693-709

Brutsaert W (1982) Evaporation into the atmosphere. Reidel, Dordrecht

Chen F, Janjic Z, Mitchell K (1997) Impact of atmospheric surfacelayer parameterizations in the new land-surface scheme of the NCEP mesoscale Eta Model. Bound Layer Meteorol 85:391-421

Chou SC, Marengo JA, Lyra AA, Sueiro G, Pesquero JF, Alves LM, Kay G, Betts R, Chagas DJ, Gomes JL, Bustamante JF, Tavares P (2011) Downscaling of South America present climate driven by 4-member HadCM3 runs. Clim Dyn. doi:10.1007/s00382011-1002-8

Chuang H-Y, Manikin G (2001) The NCEP Eta Model Post Processor: A documentation. NCEP Office Note 438, $52 \mathrm{pp}$ (http://www.emc.ncep.noaa.gov/officenotes/FullTOC.html\#2000)

Durran DD (1999) Numerical methods for wave equations in geophysical fluid dynamics. Springer, New York

Ferrier BS, Jin Y, Lin Y, Black T, Rogers E, DiMego G (2002) Implementation of a new grid-scale cloud and precipitation scheme in the NCEP Eta Model. In: 19th conference on weather analysis and forecasting/15th conference on numerical weather prediction, San Antonio. Am Meteorol Soc, pp 280-283 
Gallus WA Jr, Klemp JB (2000) Behavior of flow over step orography. Mon Weather Rev 128(4):1153-1164

Gomes JL, Chou SC (2010) Dependence of partitioning of model implicit and explicit precipitation on horizontal resolution. Meteorol Atmos Phys. doi:10.1007/s00703-009-0050-7

Gregory D, Kershaw R, Innes PM (1997) Parameterization of momentum transport by convection. II: tests in single-column and general circulation models. Q J R Meteorol Soc 123:1153-1183

Janjic ZI (1977) Pressure gradient force and advection scheme used for forecasting with steep and small scale topography. Contrib Atmos Phys 50:186-199

Janjic ZI (1979) Forward-backward scheme modified to prevent twogrid-interval noise and its application in $\sigma$ coordinate models. Contrib Atmos Phys 52:69-84

Janjic ZI (1984) Nonlinear advection schemes and energy cascade on semi-staggered grids. Mon Weather Rev 112(6):1234-1245

Janjic ZI (1990) The step-mountain coordinate: physical package. Mon Weather Rev 118(7):1429-1443

Janjic ZI (1994) The step-mountain eta coordinate model: further developments of the convection, viscous sublayer, and turbulence closure schemes. Mon Weather Rev 122(5):927-945

Janjic ZI (2002) Nonsingular Implementation of the Mellor-Yamada Level 2.5 Scheme in the NCEP Meso model. NCEP Office Note No. 437, $61 \mathrm{pp}$

Janjic ZI, Gerrity JP Sr, Nickovic S (2001) An alternative approach to nonhydrostatic modeling. Mon Weather Rev 129(5):1164-1178

Kain JS (2004) The Kain-Fritsch convective parameterization: an update. J Appl Meteor 43:170-181

Kain JS, and Fritsch JM (1993) Convective parameterization for mesoscale models: The Kain-Fritsch scheme. The representation of cumulus convection in numerical models. Meteor. Monogr., No. 24. Am Meteorol Soc, pp 165-170

Kallos G, Astitha M, Katsafados P, Spyrou C (2007) Long-range transport of anthropogenically and naturally produced particulate matter in the Mediterranean and North Atlantic: Current state of knowledge. J Appl Meteorol Clim 46:1230-1251. doi:10.1175/ JAM2530.1

Kurihara Y (1968) Note on finite difference expressions for the hydrostatic relation and pressure gradient force. Mon Weather Rev 96(9):654-656

Lacis AA, Hansen JE (1974) A parameterization of the absorption of solar radiation in the earth's atmosphere. J Atmos Sci 31:118-133

Lackmann GM, Yablonsky RM (2004) The importance of the precipitation mass sink in tropical cyclones and other heavily precipitating systems. J Atmos Sci 61(14):1674-1692

Lin SJ (1997) A finite-volume integration method for computing pressure gradient force in general vertical coordinates. Q J R Meteorol Soc 123:1749-1762

Lin SJ (1998) Reply to comments by T. Janjic on 'A finite-volume integration method for computing pressure gradient force in general vertical coordinates' (July B, 1997, 123, 1749-1762). Q J R Meteorol Soc 124:2531-2533

Lin SJ (2004) A vertically Lagrangian finite-volume dynamical core for global models. Mon Weather Rev 132(10):2293-2307

Liu WT, Katsaros KB, Businger JB (1979) Bulk parameterization of air-sea exchanges of heat and water vapor including the molecular constraints at the interface. J Atmos Sci 36(9):17221735

Mangarella PA, Chambers AJ, Street RL, Hsu EY (1973) Laboratory studies of evaporation and energy transfer through a wavy airwater interface. J Phys Oceanogr 3(1):93-101

Marshall J, Adcroft A, Campin J-M, Hill C, White A (2004) Atmosphere-ocean modeling exploiting fluid isomorphisms. Mon Weather Rev 132(12):2882-2894
McDonald BE, Horel JD, Stiff CJ, Steenburgh WJ (1998) Observations and simulations of three downslope wind events over the northern Wasatch Mountains. In: 16th conference on weather analysis and forecasting. Am Meteorol Soc, pp 62-64

Mellor GL, Yamada T (1982) Development of a turbulence closure model for geophysical fluid problems. Rev Geophys Space Phys 20:851-875

Mesinger F (1974) An economical explicit scheme which inherently prevents the false two-grid-interval wave in the forecast fields. In: Proc Symp "Difference and spectral methods for atmosphere and ocean dynamics problems", Academy of Sciences, Novosibirsk, 17-22 September 1973; Part II, pp 18-34

Mesinger F (1977) Forward-backward scheme, and its use in a limited area model. Contrib Atmos Phys 50:200-210

Mesinger F (1984) A blocking technique for representation of mountains in atmospheric models. Riv Meteorol Aeronautica 44:195-202

Mesinger F (1993) Forecasting upper tropospheric turbulence within the framework of the Mellor-Yamada 2.5 closure. Res Act Atmos Ocean Model 18:4.28-4.29

Mesinger F (2000) Numerical methods: the Arakawa approach, horizontal grid, global, and limited-area modeling. In: DA Randall (ed) General circulation model development: past, present and future. International Geophysics Series, vol 70. Academic Press, New York, pp 373-419

Mesinger F (2004a) The steepness limit to validity of approximation to pressure gradient force: any signs of an impact? Combined preprints $\mathrm{CD}-\mathrm{ROM}$ of the 20th conference on weather analysis and forecasting/16th conference on numerical weather prediction. Am Meteorol Soc Paper P1.19

Mesinger F (2004b) The Eta model: design, history, performance, what lessons have we learned? In: Symposium on the 50th anniversary of operational numerical weather prediction, Univ. of Maryland, College Park, 14-17 June 2004. http://www.ncep. noaa.gov/nwp50/Presentations/)

Mesinger F (2008) Bias adjusted precipitation threat scores. Adv Geosci 16:137-143

Mesinger F (2010) Several PBL parameterization lessons arrived at running an NWP model. In: Intern. conference on planetary boundary layer and climate change, IOP Publishing, IOP Conference Series: Earth and Environmental Science 13. doi: 10.1088/1755-1315/13/1/012005 (http://iopscience.iop.org/1755-13 $15 / 13 / 1 / 012005)$

Mesinger F, Black TL (1992) On the impact on forecast accuracy of the step-mountain (eta) vs. sigma coordinate. Meteorol Atmos Phys 50:47-60

Mesinger F, Janjic ZI (1985) Problems and numerical methods of the incorporation of mountains in atmospheric models. In: Engquist BE, Osher S, Somerville RCJ (eds) Large-scale computations in fluid mechanics. Lect Appl Math 22:81-120

Mesinger F, Jovic D (2002) The Eta slope adjustment: contender for an optimal steepening in a piecewise-linear advection scheme? Comparison tests. NCEP Office Note 439 (http://www.emc. ncep.noaa.gov/officenotes)

Mesinger F, Jovic D (2004) Vertical coordinate, QPF, and resolution. In: The 2004 workshop on the solution of partial differential equations on the sphere, vol 2. Frontier Research Center for Global Change (FRCGC), Yokohama, 20-23 July 2004. CDROM (http://www.jamstec.go.jp/frcgc/eng/workshop/pde2004/ agenda.html)

Mesinger F, Lazic L (2004) Water vapor sources and sinks, and hydrometeor loading in the Eta model. Res Act Atmos Ocean Model 34:5.21-5.22 (http://collaboration.cmc.ec.gc.ca/science/ wgne/)

Mesinger F, Lobocki L (1991) Sensitivity to the parameterization of surface fluxes in NMC's eta model. In: 9th conference on 
numerical weather prediction, Denver. Am Meteorol Soc, pp 213-216

Mesinger F, Popovic J (2010) Forward-backward scheme on the B/E grid modified to suppress lattice separation: the two versions, and any impact of the choice made? Meteorol Atmos Phys 108:1-8. doi:10.1007/s00703-010-0080-1

Mesinger F, Janjic ZI, Nickovic S, Gavrilov D, Deaven DG (1988) The step-mountain coordinate: model description, and performance for cases of Alpine lee cyclogenesis and for a case of an Appalachian redevelopment. Mon Weather Rev 116(7):14931518

Mesinger F, Wobus RL, Baldwin ME (1996) Parameterization of form drag in the Eta Model at the National Centers for Environmental Prediction. In: 11th conference on numerical weather prediction, Norfolk. Am Meteorol Soc, pp 324-326

Mesinger F, Chou SC, Gomes J, Jovic D, Lazic L (2008) A near finite-volume Eta and a case of severe zonda downslope windstorm. In: Fall colloquium on the physics of weather and climate: regional weather predictability and modelling, The Abdus Salam International Centre for Theoretical Physics, Miramare, 29 September-10 October 2008 (http://cdsagenda5. ictp.trieste.it/askArchive.php?subtalk $=1 \&$ base $=$ agenda\&categ $=$ a07175\&id=a07175s10t11/lecture_notes)

Morelli S, Parmiggiani F (2012) Eta model simulations and AMSR images to study an event of polynya at Terra Nova Bay, Antarctica. In: Berger A, Mesinger F, Sijacki Dj (eds) Climate change, inferences from paleoclimate and regional aspects. Springer (in press)

Norte FA, Ulke AG, Simonelli SC, Viale M (2008) The severe zonda wind event of 11 July 2006 east of the Andes Cordillera (Argentine): a case study using the BRAMS model. Meteorol Atmos Phys 102:1-14

Reinecke PA, Durran D (2009) The overamplification of gravity waves in numerical simulations to flow over topography. Mon Weather Rev 137:1533-1549

Russell GL (2007) Step-mountain technique applied to an atmospheric C-grid model, or how to improve precipitation near mountains. Mon Weather Rev 135(12):4060-4076

Schwarzkopf MD, Fels SB (1991) The simplified exchange method revisited: an accurate, rapid method for computation of infrared cooling rates and fluxes. J Geophys Res 96:9075-9096

SCOR WG 110 (2000) Intercomparison and validation of oceanatmosphere energy flux fields. In: Taylor PK (ed) Final report of the joint WCRP/SCOR Working Group on Air-Sea Fluxes. WMO, Geneva, WMO/TD No. 1036
Seluchi ME, Norte FA, Satyamurty P, Chou SC (2003) Analysis of three situations of the foehn effect over the Andes (zonda wind) using the Eta-CPTEC regional model. Weather Forecast 18(3):481-501

Spyrou C, Mitsakou C, Kallos G, Louka P, Vlastou G (2010) An improved limited-area model for describing the dust cycle in the atmosphere. J Geophys Res 115:D17211. doi:10.1029/2009 JD013682

Steppeler J, Bitzer HW, Janjic Z, Schättler U, Prohl P, Gjertsen U, Torrisi L, Parfinievicz J, Avgoustoglou E, Damrath U (2006) Prediction of clouds and rain using a $z$-coordinate nonhydrostatic model. Mon Weather Rev 134(12):3625-3643

Takacs LL (1985) A two-step scheme for the advection equation with minimized dissipation and dispersion errors. Mon Weather Rev 113:1050-1065

Thuburn J (1993) Use of a flux-limited scheme for vertical advection in a GCM. Q J R Meteor Soc 119:469-487

Tiedtke M (1989) A Comprehensive mass flux scheme for cumulus parameterization in large-scale models. Mon Weather Rev 117(8):1779-1800

Tremback CJ, Walko RL (2004) Implementing very-high resolution capabilities into a mesoscale atmospheric model: new capabilities for the regional atmospheric modeling system (RAMS). Extended abstract in mesoscale and CFD modeling for military applications, Jackson State University (http://www.rwic. und.edu/ tilley/extabstracts/Paper1.4.pdf)

Veljovic K, Rajkovic B, Fennessy MJ, Altshuler EL, Mesinger F (2010) Regional climate modeling: Should one attempt improving on the large scales? Lateral boundary condition scheme: any impact? Meteor Zeitschrift 19:237-246. doi:10.1127/09412948/2010/0460

Walko RL, Avissar R (2008) The ocean-land-atmosphere model (OLAM). Part II: formulation and tests of the nonhydrostatic dynamic core. Mon Weather Rev 136(11):4045-4062

Zilitinkevich SS (1995) Non-local turbulent transport: Pollution dispersion aspects of coherent structure of convective flows. In: Power H, Moussiopoulos N, Brebbia CA (eds) Air pollution III. Air pollution theory and simulation, vol I. Computational Mechanics Publications, Southampton, pp 53-60

Zoras S, Evagelopoulos V, Pytharoulis I, Kallos G (2010) Development and validation of a novel-based combination operational air quality forecasting system in Greece. Meteorol Atmos Phys 106(3-4):127-133. doi:10.1007/s00703-0100058-z 